\title{
Relations Between Bicultural Attitudes, Paternal Versus Maternal Acceptance, and Psychological Adjustment of Ethnic Minority Youth in Bangladesh
}

\author{
Abdul Khaleque ${ }^{1}$ \\ University of Connecticut, USA \\ Muhammad Kamal Uddin \\ University of Dhaka, Bangladesh \\ Rumana Aktar \\ University of Chittagong, Bangladesh
}

\begin{abstract}
The purpose of this study was to explore the effects of perceived paternal and maternal acceptance on the bicultural orientations and psychological adjustment of ethnic-minority young adults in Bangladesh. The study was based on a sample of 412 young adults (mean age 22 years), consisting of $40 \%$ women and $60 \%$ men from 18 tribal subgroups in Bangladesh. Measures used were Parental Acceptance-Rejection Questionnaire (PARQ), Bicultural Attitude Scale (BAS) and Personality Assessment Questionnaire (PAQ). Results showed that there are significant positive correlations between perceived parental (paternal and maternal) acceptance, heritage culture, and psychological adjustment of the respondents. Results further showed that perceived paternal acceptance has independent and stronger effect than perceived maternal acceptance on the bicultural orientations and psychological adjustment of the minority young adults in Bangladesh.
\end{abstract}

Keywords: bicultural attitudes, ethnicity, heritage culture, national culture, maternal acceptance, paternal acceptance, psychological adjustment.

Contact and interactions between individuals of different cultures and subcultures are increasing rapidly due to social changes and mobility of people nationally and internationally (Nguyen \& Benet-Martinez, 2013). Growing number of people worldwide are becoming either bicultural or multicultural with increasing trend of migration. According to the International Organization of Migration (IOM, 2020), an estimated number of international migrants in the year 2020 was about 272 million. As a result of increasing exposure to other cultures, many people are going through the process of internalization of more than one culture and becoming bicultural or multicultural (Benet-Martínez, 2012). The bicultural and multicultural individuals can be of different types, such as immigrants, refugees, indigenous people, ethnic minorities and so forth (Berry, 2006).

Acculturation is a process through which individuals learn about other cultures and gradually acquire a bicultural or a multi-cultural identity (Berry, 1997, 2006). Earlier researchers

\footnotetext{
${ }^{1}$ Correspondent Author E-Mail: Abdul.khaleque@uconn.edu
} 
considered biculturalism as a unidirectional process involving acquisition of the new cultural values through interaction with members of the host culture(s), along with loss of values from the culture of origin or heritage culture (Gordon, 1964). Current proponents of the bicultural perspective, however, view acculturation as a combination of both heritage and host cultural values in which almost every aspect of behavior could change, including food habits, dress patterns, language, and other behaviors and socio-cultural values (Berry, 2005; Oetting \& Beauvais, 1990).

According to Berry, biculturalism and acculturation are interdependent concepts. Interactions between the national culture (dominant culture) and heritage culture can result in four possible types of acculturation processes, such as assimilation (unicultural orientation toward the national culture only), separation (unicultural orientation toward the heritage culture only), integration (bicultural orientation toward both the national culture and heritage culture), and marginality (alienation from both heritage culture and national culture) (Berry, 2006).Thus biculturalism is an acculturation strategy that depends on the process of integration, in which people adopt both the national culture and their heritage culture of origin and combine the two at the same time (Berry et al., 2006; Nguyen \& Benet-Martinez, 2013).

A number of researchers have emphasized the importance of parent-child relationships, especially parental acceptance-rejection, for understanding biculturalism and multiculturalism, and developmental issues, such as personality development, and psychological adjustment among ethnic minorities globally (Benet-Martinez et al., 2006; Khaleque et al., 2015; Kim et al., 2007). In this context, the present study was designed to explore some assumptions of the interpersonal acceptance-rejection theory (Rohner, 1986, 2021). Interpersonal acceptance-rejection theory (IPARTheory) is an evidence-based theory of socialization and lifespan development of children and adults universally (Khaleque \& Ali, 2017; Roher \& Khaleque, 2010; Rohner et al., 2013). The theory aims to predict and explain major causes, consequences, and correlates of interpersonal acceptance and rejection--- especially by parents and other attachment figures. In IPARTheory, parental acceptance-rejection refers to a bipolar dimension, with parental acceptance at the positive end of the continuum and the parental rejection at the negative end. Parental acceptance refers to warmth, affection, love, care, comfort, support or nurturance that parents can feel or express toward their children. On the other hand, Parental rejection refers to the absence or withdrawal of warmth, affection, or love by the parents towards their children. The theory predicts that parental acceptance has consistent positive effects, and parental rejection has consistent negative effects on the psychological adjustment, attitudes, and behavior of both children and adults worldwide (Rohner, 1986; Rohner \& Khaleque, 2005, 2010). In addition, the interpersonal acceptance-rejection theory predicts that paternal accepting-rejecting behaviors often have as strong or even stronger implications for children's and adults' psychological wellbeing and socioemotional development than do maternal accepting -rejecting behaviors (Khaleque, 2021; Rohner, 2021). Worldwide cross-cultural meta-analytic research suggests that parental acceptance and rejection are of utmost importance for understanding children's psychological adjustment, personality, and behavioral development (Khaleque, 2015, 2017, 2021; Khaleque \& Ali, 2017).

Researchers have also emphasized the importance of biculturalism and multiculturalism for understanding developmental issues, including parent-child relationships, especially parental acceptance-rejection, personality development, and psychological adjustment among ethnic minorities globally (Benet-Martinez et al., 2006; Khaleque, 2020, 2021; Khaleque et al., 2015; Kim et al., 2007). A meta-analysis on biculturalism and psychological adjustment showed that bicultural orientation has stronger positive relationship with individuals' psychological adjustment than unicultural orientation (Nguyen \& Benet-Martinez, 2013). However, the results of research about the implications of acculturation and cultural orientations on the psychological well-being have not 
been sufficiently clear (Balidemaj, 2016). For example, Sam (2000) found that cultural orientations such as assimilation and integration account for only about $4 \%$ of the variance in psychological wellbeing. Assessment of bicultural orientations seems to be an important issue for understanding the process of integration among different ethno-cultural groups in any multi-ethnic and multiracial country with people of many cultures and subcultures living side by side for generation after generation (Khaleque, 2016; Khaleque et al., 2015). Although a couple of studies have been done on acculturation problems of migrant families, but not enough empirical studies can be found on the acculturation problems of ethnic minorities with the main stream population in their home countries (Balidemaj, 2016; Benet-Martinez et al., 2006; Kim et al., 2007). Some researchers have emphasized the importance of biculturalism and multiculturalism for understanding sociocultural developmental complexity and mental health-related problems including anxiety, depression, alcohol abuse, drug addiction, delinquent behavior, low self-esteem, and suicidal tendencies (e.g., Benet-Martinez et al., 2006). Although biculturalism, especially of immigrant population, has recently received a great deal of attention, and a good number of studies have been conducted in the Western countries (Benet-Martinez et al., 2006; Prez-Brena et al., 2018), its impacts on individuals' psychological wellbeing and adjustment remains unclear (Nguyen \& Benet-Martinez, 2013).

Because a growing number of people worldwide are becoming either bicultural or multicultural with increasing trend of migration, the importance of biculturalism or multiculturalism has been emphasized by several researchers for understanding sociocultural developmental complexity (Benet-Martinez et al., 2006; Juang \& Schachner, 2020) and mental health-related problems including anxiety, depression, alcohol abuse, drug addiction, delinquent behavior, low self-esteem, and suicidal tendencies (Fazel \& Betancourt, 2018; Sorenson \& Golding, 1988). However, most of the studies on acculturation focused on the cultural orientations of immigrant population and few studies measured cultural orientations of any ethnic or tribal population who have been living generations after generations in the same country with distinctly different cultural identities from the main stream population of any multicultural nation or society (Khaleque, 2016, 2020, 2021). For example, little or no research has been done on bicultural problems of native ethnic minority population, especially in developing countries including Bangladesh (Balidemaj, 2016; Khaleque, 2020; Rasool \& Zhang, 2020). The following section contains a brief description of the minority ethnic population in Bangladesh:

\section{Ethnic Minority Population in Bangladesh}

The current total population of Bangladesh is approximately 166 million (Worldometer, 2020). Nearly $98 \%$ of them belong to the major ethnic group (i.e., the Bengali). Racially, Bengalis originated from Indo-Aryan human group. About $2 \%$ of the total population of Bangladesh consists of different ethnic and tribal subgroups. Major ethnic subgroups include Chakma, Marma, Santal, Garo, and Tripura. Racially, they consist of diverse ethnic communities including TibetoBurman, Sino-Tibetan, and Dravidian races. They live in different regions of Bangladesh including the southeastern (Chittagong Hill Tracts), northeastern (Sylhet), northwestern (Rajshahi), northern (Dinajpur), and north central (Mymensing) regions of the country. They speak different dialects, although most of them can read and speak Bangla--- the major language of Bangladesh. Each ethnic group has distinctly different cultural identity and lifestyle including language, family and marriage system, religious and cultural festivals, food habit, dress pattern, works, income and employment (see figures 1, 2 and 3). 


\section{Images of Different Ethnic Groups in Bangladesh}

\section{Figure 1}

Bengali Women Participating in the Spring Festival

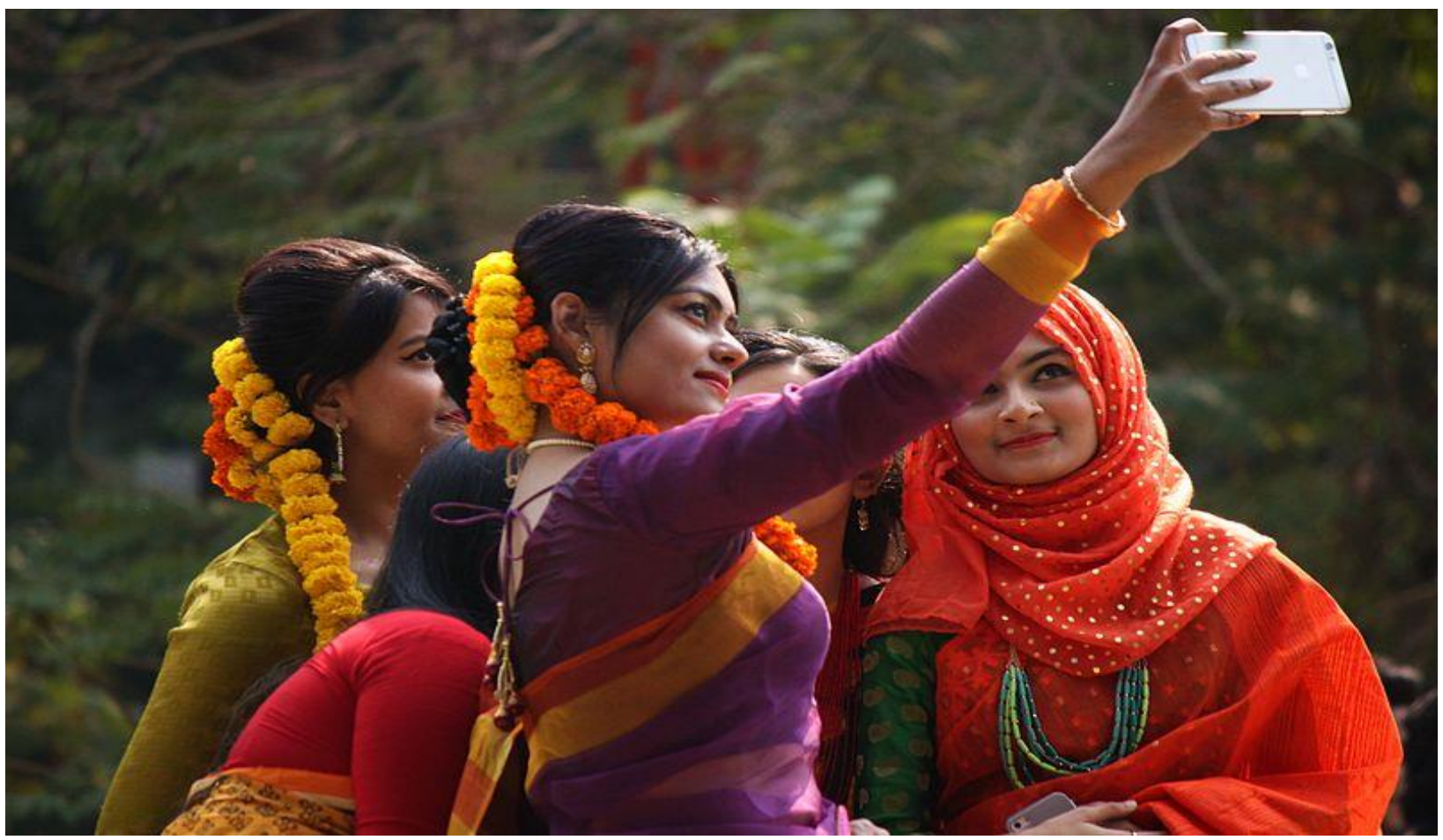

Note. Adapted from https://www.showmeneel.blogspot.com

\section{Figure 2.}

\section{Marma Tribal Women Performing Dance}

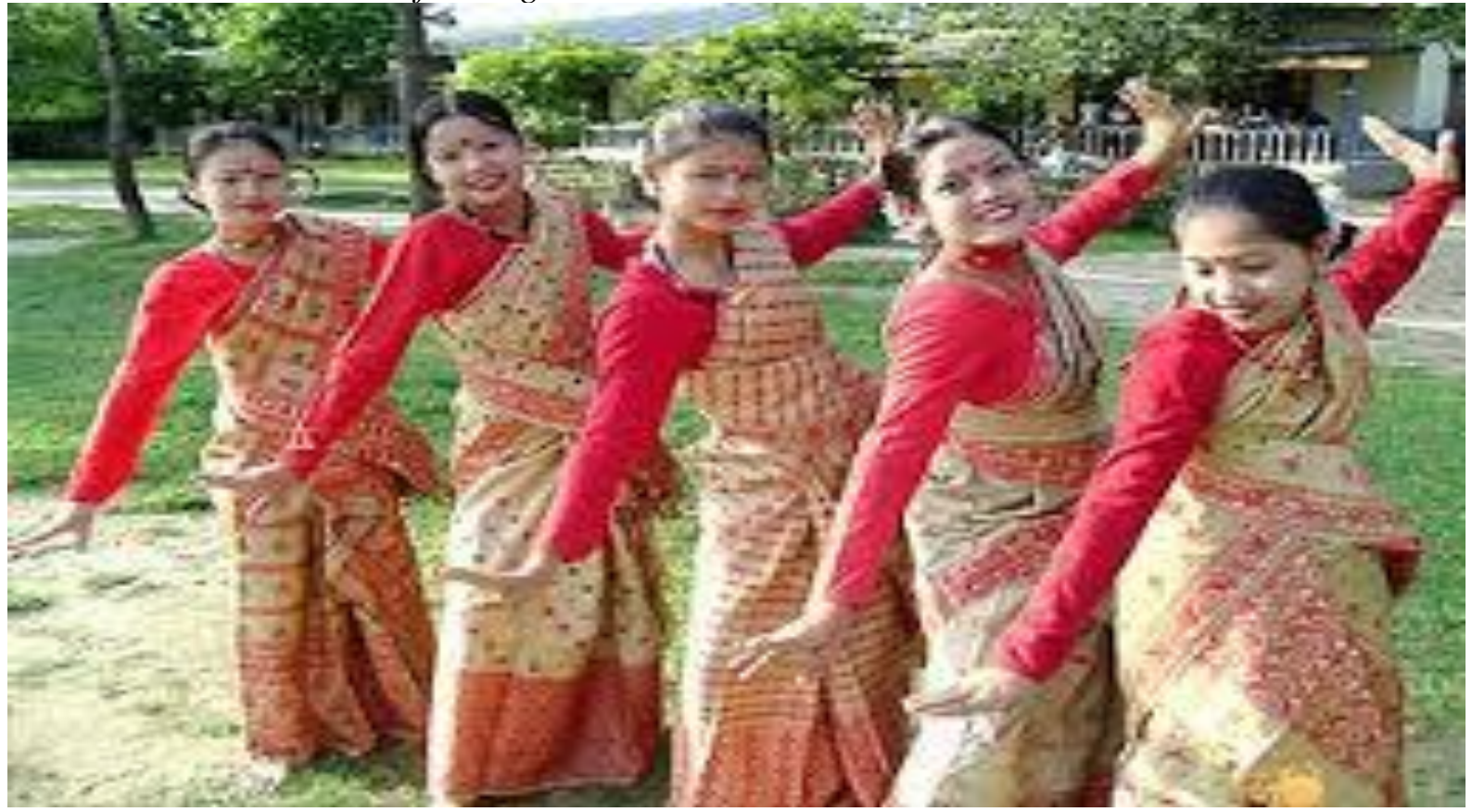

Note. Adapted from https://www.showmeneel.blogspot.com 


\section{Figure 3}

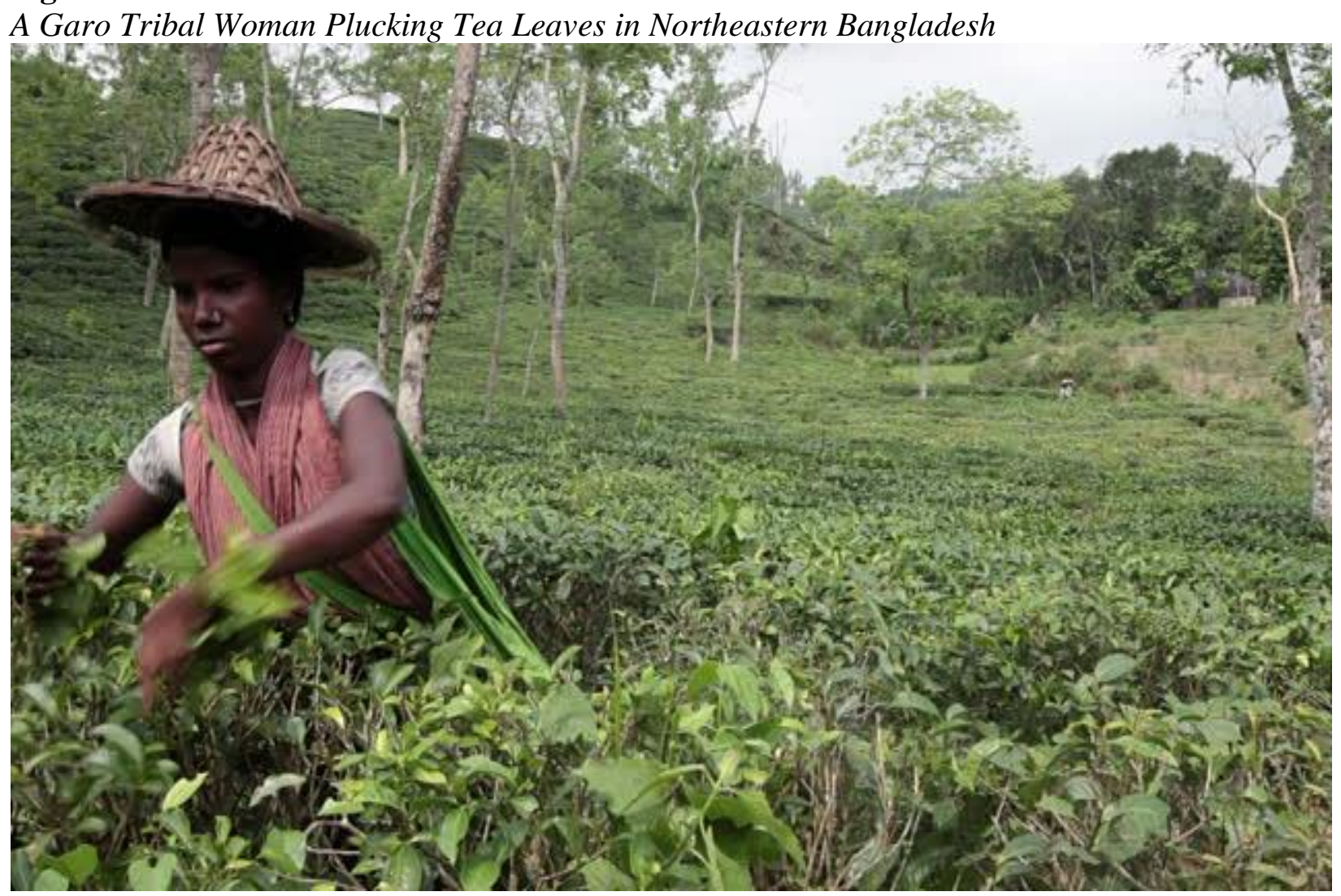

Note. Adapted from https://www.showmeneel.blogspot.com

The Ethnic minority groups believe in different religions, namely Buddhism, Hinduism, Christianity, and Animism. As noted above, individuals of almost all the tribal groups, included in this study, have their own ethnocultural beliefs and values which are different from the national cultural identity of the majority ethnic group, consisting of Bengali language, music, arts, dress patterns, food habits, marriage systems, and so on. However, as the tribal children grow up, they come in contact with the main stream Bengali culture and learn it with their own ethnic culture (Khaleque et al., 2016). Gradually, the minority ethnic population develop a bicultural identity (Benet-Martinez \& Haritatos, 2021; Meca et al., 2019; Partha, 2014). Research findings indicate that formation of a bicultural identity involves blending together the components of two different cultures. According to some researchers (e.g., Friedman, 2012; Khaleque, 2016) psychosocial development of bicultural individuals is shaped by integration of two different cultures, which might also be true for the Bangladeshi tribal sample in this study.

\section{Present Study}

As discussed earlier, a number of researchers have emphasized the importance of parental acceptance-rejection, and biculturalism and multiculturalism for understanding developmental issues, including children's and adults' psychological adjustment (Benet-Martinez et al., 2006; Khaleque, 2011, 2020, 2021). But, so far little or no work has been done on the outcomes of parental acceptance-rejection on bicultural attitudes and psychological adjustment of native ethnic minority population, especially in developing countries including Bangladesh. In this context, the 
present study examined some predictions of the interpersonal acceptance-rejection theory (Rohner, 2021) on the Bangladeshi ethnic minority youth. The study specifically explored the following research questions:

1. Are there significant relations between parental acceptance, maternal acceptance, bicultural attitudes, and psychological adjustment of the Bangladeshi ethnic minority youth?

2. Are there significant independent effects of paternal and maternal acceptance on the bicultural attitudes, and psychological adjustment of the respondents?

3. Are there significant independent effects of bicultural attitudes on the psychological adjustment of the youth?

\section{Methods}

\section{Participants}

The sample consisted of 412 youth (40\% women and $60 \%$ men) from five major ethnic subgroups (i.e., Chakma, Marma, Garo, Santal, and Tripura) in Bangladesh. These ethnic communities are from Tibeto-Burman, Sino-Tibetan, and Dravidian races. Although these communities use different dialects, all the participants can speak Bangla, which is the national language of Bangladesh. The mean age of the sample was 22 years $(S D=2$ years) ranging from 18 to 30. All participants were university students and their educational levels varied from undergraduate $(88 \%)$ to graduate $(12 \%)$. Majority (approximately $80 \%$ ) of the participants were from middle class family background. Among the participants $97 \%$ were single and $3 \%$ were married. With respect to religious affiliations, about 53\% participants were Buddhist, about $27 \%$ were Christian, about $18 \%$ were Hindus and rest $2 \%$ participants belonged to other religions. Majority $(85 \%)$ of the participants were from joint families. The respondents were selected conveniently from six major universities in Bangladesh. They were recruited in August of 2015 in the classroom settings after obtaining their informed consent. The questionnaires were administered to the respondents in classes with the permission of the concerned teachers.

\section{Procedures}

Data were collected from the sample using following four questionnaires [(1) The Bicultural Attitude Scale for Youth (BAS for Youth), (2 and 3) Adult version of Parental Acceptance-rejection Questionnaire for Mothers and Fathers (Adult PARQ: Mother and Father version), and (4) Adult version of the Personality Assessment Questionnaire (Adult PAQ)] discussed below. The questionnaires were administered to the respondents during classes with the permission of the concerned teachers and willing consent of the students. The questionnaires were administered in the following order: Adult PARQ: Mother version, BAS, Adult PAQ, and Adult PARQ: Father version. The two versions of the PARQ were separated by the BAS, and PAQ in order to minimize halo-effect bias, where students might not tend to respond to the father version of the PARQ in specific ways that they responded to the mother version of the PARQ. 


\section{Measures}

As mentioned above the following measures were used to assess the bicultural attitudes, parental acceptance-rejection (mother and father version), and psychological adjustment of the respondents. Description of each of the four scales are as follows:

The Bicultural Attitude Scale for Youth (BAS for Youth). The scale consists of 16-item self-report questionnaire designed to measure individuals' unicultural and bicultural orientations (Khaleque, 2006, 2008, 2014). The BAS was developed on the basis of content of focus group discussions on biculturalism (Cortes et al., 1994). The original scale was developed in 2006, which was revised twice, first in 2011 and then in 2014 (Khaleque, 2011, 2014). The latest revised version was used in this study. This version consisted of 16 items (Khaleque, 2014, 2016). First eight items (items 1-8) measure an individual's orientation toward national culture (or host culture), and the last eight items (items 9-16) measure an individual's orientation toward ethnic culture or heritage culture. On each item, individuals respond to a four-point Likert scale ranging from (1) "not at all" to (4) "very much." The total score of the first eight items (1-8) represents an individual's orientation toward the national culture or host culture. The total score of the last eight items (9-16) indicates an individual's orientation toward ethnic culture or heritage culture. Possible scores on the BAS for each of the national culture and heritage culture spread from a minimum of 8 to a maximum of 32 with a midpoint of 20 . The scale is conceptually designed in such a way that scores at or above the midpoint on the cultural values of the national culture (i.e., above the midpoint of the total score on items 1 through 8) indicate unicultural orientation toward the national culture, and scores at or above the midpoint on the cultural values of the heritage culture (i.e. above the midpoint of the total score on items 9 through 16) indicate unicultural orientation toward heritage culture. On the other hand, scores at or above the midpoint on the cultural values of both heritage culture and national culture indicate bicultural orientation. Whereas, scores below the midpoint on the cultural values of both heritage culture and national culture indicate cultural alienation or marginalization. The BAS Youth version is available in five languages (i.e., Bangla, English, Italian, Korean, and Urdu) and have been used to study the cultural orientations of immigrant or ethnic populations in several countries of Asia, Europe, and North America. Preliminary evidence about the validity of the BAS comes from an exploratory factor analysis of the instrument (Khaleque, 2008, 2016). Available evidence from several other studies (Khaleque, 2011, 2016; Khaleque et al., 2008; Podio-Guidugli, 2010) shows that the scale is highly reliable (alpha coefficients vary from .80 to .86), and valid (factorial validity ranges from .62 to .96). In the present study, Cronbach's alpha coefficients for the Bangla version of BAS was .79 for the national culture subscale and .85 for the heritage culture subscale (Uddin et al., 2014).

Adult version of the Parental Acceptance-Rejection Questionnaire for Mothers and Fathers (Adult PARQ: Mother and Father). These self-report measures consist of 24 items each. The two versions are virtually identical except for reference to mother's behavior versus father's behavior and are designed to measure individuals' perceptions of maternal and paternal acceptance or rejection. In both versions, respondents are asked to reflect on their perceptions of their mothers' or fathers' behaviors toward them when they were about 7 through 12 years old. Both measures consist of four subscales each: (a) paternal or maternal Warmth/Affection (e.g., "My father [mother] said nice things about me"), (b) Hostility/Aggression (e.g., "My father [mother] got angry at me easily"), (c) Indifference/Neglect (e.g., "My father [my mother] paid no attention to me" and (d) Undifferentiated Rejection (e.g., "My father [mother] did not really love me"). 
In both PARQ Father and Mother versions items are scored on 4-point Likert-type scales with 4 (almost always true), 3 (sometimes true), 2 (rarely true) and 1 (almost never true). Scores on the four acceptance-rejection subscales are summed after reverse scoring the Warmth/Affection scale to create a measure of coldness and lack of affection. Similarly, seven of the items on the indifference/neglect scale (which are worded positively) must be reverse scored to make them consistent with the other negatively worded items on that scale. This produces an overall measure of perceived acceptance-rejection that ranges from a low of 24 (maximum perceived acceptance) to a high of 96 (maximum perceived rejection). Scores at or above 60 denote the perception of qualitatively more rejection than acceptance.

The PARQ is available in more than 40 languages, and has been used in over 1000 studies in approximately 60 nations and ethnic groups worldwide. Analyses of the reliability and validity of the PARQ show the instrument to be unusually robust in cross-cultural research (Khaleque \& Ali, 2017). A meta-analysis of 7,152 respondents from Africa, Asia, the Caribbean, and major American ethnic groups (i.e., African Americans, Asian Americans, European Americans, and Hispanic Americans), revealed the mean weighted effect size of coefficient alpha, aggregated across all versions of the PARQ, was .89 (Khaleque \& Rohner, 2002). Moreover, mean test-retest reliability across time periods ranging from three weeks through seven years (median, 15 months) is .62 (Khaleque \& Rohner, 2000). The alpha coefficient of the PARQ Bangla version used in the present study was .88 (Uddin \& Aktar, 2014a).

Adult version of the Personality Assessment Questionnaire (Adult PAQ). The Adult PAQ is a self-report questionnaire designed to assess individuals' perceptions of their psychological adjustment/maladjustment (Rohner \& Khaleque, 2005; Rohner, 2020). The questionnaire consists of seven subscales related to seven personality dispositions: hostility/ aggression, dependency, negative self-esteem, negative self-adequacy, emotional unresponsiveness, emotional instability, and negative worldview). The entire scale consists of 42 items, 6 items for each of the seven subscales. Sample items for each of the seven subscale include: I think about fighting or being unkind (Hostility/Aggression), I like my friends to show a lot of affection toward me (Dependency), when I meet someone I do not know, I think s(he) is better than I am (Negative Self-Esteem), I feel I cannot do things well (Negative Self-Adequacy), I have difficulty showing people how I really feel (Emotional Unresponsiveness), I feel bad or get angry when I try to do something and I cannot do it (Emotional Instability) and I see life as full of dangers (Negative Worldview). The items of the entire scale are rated on a four-point Likert scale ranging from almost always true (4) to almost never true (1). A higher total score in all seven sub-scales indicate lower psychological maladjustment and vice-versa. The sum of scores on the PAQ can spread from a low of 42 (indicating high psychological adjustment) to a high of 168 (indicating serious psychological maladjustment) The measure is designed in such a way that scores at or above the test's midpoint of 105 reveals psychological maladjustment, and any score below the midpoint reveals psychological adjustment. Extensive evidence reported in Rohner and Khaleque (2005) indicates the robust reliability and validity of the Adult PAQ for use in cross-cultural research. Findings of several studies show that coefficient alpha for the PAQ ranges from .81 to 91 (Khaleque \& Ali, 2017; Rohner \& Carrasco, 2014; Rohner \& Khaleque, 2005). The alpha coefficient of the PAQ Bangla version used in the present study was .84 (Uddin \& Aktar, 2014b). 


\section{Results}

Cultural orientations of Bangladeshi ethnic minority youths were assessed on the basis of the scores in the items of BAS, which measure an individual's orientation toward national culture and heritage culture. The number of participants according to their cultural orientations (i.e., bicultural orientation, unicultural orientation toward heritage culture, unicultural orientation toward national or host culture, and culturally marginal) are depicted in Table 1.

Table 1

Cultural Orientations of Bangladeshi Ethnic Minority Youth

\begin{tabular}{lccc}
\hline Cultural orientations & $n$ & $\%$ & $\chi^{2}$ \\
\hline Bicultural orientation & 236 & $57 \%$ & \\
Unicultural orientation (toward heritage culture) & 162 & $39 \%$ & $385.18^{* * *}$ \\
Unicultural orientation (toward national culture) & 13 & $3 \%$ & \\
Culturally marginal or isolate & 1 & $0.24 \%$ & \\
\hline
\end{tabular}
$* * * p<.001$.

As shown in Table 1, the largest number (57\%) of the minority ethnic youth tended to be biculturally oriented, and the second largest number (39\%) of them were uniculturally oriented toward the heritage culture, a smaller number of them (only 3\%) were uniculturally oriented toward the national culture, and less than one percent of them were culturally alienated or marginal. These differences are statistically significant. To determine whether Bangladeshi ethnic minority women and men differ in the ratings of importance of the heritage and national culture the independent $t$ test was performed (see Table 2).

Table 2

Mean Differences Between the Ratings of Importance of the Heritage Culture and the National Culture of the Minority Young Men and Young Women

$\begin{array}{lllllcc}\text { Gender } & n & M & S D & t(410) & p & \begin{array}{c}\text { Cohen's } \\ d\end{array} \\ \end{array}$

Heritage culture

\begin{tabular}{cccccccc} 
& Women & 166 & 29.85 & 3.75 & & \\
& Men & 246 & 29.20 & 3.54 & & & \\
National culture & Women & 166 & 20.39 & 3.72 & & & .03 \\
& Men & 246 & 20.53 & 4.71 & & & \\
\hline
\end{tabular}

Table 2 revealed that the overall mean score of importance of heritage culture was marginally significantly higher for women than that of men. Furthermore, there was no significant difference between the mean scores of the ratings of importance by men and women about the national culture. Furthermore, to get a clear illustration of young Bangladeshi ethnic minority women and men's attitude toward heritage and host culture the detailed response patterns of respondents on the items of BAS was examined (see Table 3). 
Table 3 showed that in comparison to young men, significantly greater proportion of the young women expressed stronger affinity for some components of their heritage culture, such as cultural identity, food, dress, language, and marriage system. On the other hand, significantly greater proportion of the young men expressed stronger affinity for some components of the national culture, including cultural values, language, dress, and marriage than the young women.

Table 3

Distributions of Response Patterns of the Male and Female Respondents on the Items of the BAS

\begin{tabular}{|c|c|c|c|c|c|c|c|}
\hline \multirow[t]{2}{*}{ 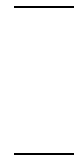 } & \multirow[t]{2}{*}{ Items } & \multirow[t]{2}{*}{ Gender } & \multicolumn{4}{|c|}{ Response options } & \multirow{2}{*}{$\begin{array}{l}\text { Contingency } \\
\text { coefficient }\end{array}$} \\
\hline & & & $\begin{array}{l}\text { Not at } \\
\text { All }\end{array}$ & $\begin{array}{c}\text { A } \\
\text { Little }\end{array}$ & Somewhat & $\begin{array}{l}\text { Very } \\
\text { much }\end{array}$ & \\
\hline \multirow[t]{2}{*}{1} & $\begin{array}{l}\text { How much are the } \\
\text { values of the }\end{array}$ & W & 15 & 88 & 48 & 15 & \multirow{2}{*}{$.158 *$} \\
\hline & $\begin{array}{l}\text { national culture a } \\
\text { part of your life? }\end{array}$ & M & 44 & 101 & 67 & 34 & \\
\hline \multirow[t]{2}{*}{2} & $\begin{array}{l}\text { How important is it } \\
\text { to you to celebrate }\end{array}$ & W & 4 & 18 & 78 & 66 & \\
\hline & $\begin{array}{l}\text { holidays in the ways } \\
\text { people do } \\
\text { nationally? }\end{array}$ & M & 5 & 33 & 99 & 109 & .072 \\
\hline \multirow[t]{2}{*}{3} & How important is it & W & 21 & 76 & 50 & 19 & \multirow[b]{2}{*}{.117} \\
\hline & $\begin{array}{l}\text { with values of the } \\
\text { national culture? }\end{array}$ & M & 52 & 96 & 66 & 32 & \\
\hline \multirow[t]{2}{*}{4} & $\begin{array}{l}\text { How important is it } \\
\text { to you to speak in }\end{array}$ & W & 4 & 28 & 96 & 38 & \multirow[b]{2}{*}{$.140^{*}$} \\
\hline & $\begin{array}{l}\text { the national } \\
\text { language of your } \\
\text { country? }\end{array}$ & M & 7 & 58 & 107 & 74 & \\
\hline \multirow[t]{2}{*}{5} & How important is it & W & 20 & 88 & 47 & 11 & \multirow[b]{2}{*}{$.157 *$} \\
\hline & $\begin{array}{l}\text { dresses of the } \\
\text { national culture? }\end{array}$ & M & 54 & 104 & 61 & 27 & \\
\hline \multirow[t]{2}{*}{6} & $\begin{array}{l}\text { How much do you } \\
\text { enjoy eating the }\end{array}$ & W & 8 & 61 & 68 & 29 & \multirow[b]{2}{*}{.061} \\
\hline & $\begin{array}{l}\text { foods of the main } \\
\text { stream population } \\
\text { of your country? }\end{array}$ & M & 14 & 98 & 86 & 48 & \\
\hline \multirow[t]{2}{*}{7} & How much do you & W & 5 & 38 & 75 & 48 & \multirow[b]{2}{*}{.119} \\
\hline & $\begin{array}{l}\text { enjoy the music of } \\
\text { the national culture? }\end{array}$ & M & 12 & 77 & 105 & 52 & \\
\hline \multirow[t]{2}{*}{8} & $\begin{array}{l}\text { How important is it } \\
\text { to you to marry }\end{array}$ & W & 130 & 22 & 6 & 8 & \multirow[b]{2}{*}{$.240 * * *$} \\
\hline & $\begin{array}{l}\text { someone belonging } \\
\text { to the national } \\
\text { culture? }\end{array}$ & $\mathrm{M}$ & 138 & 44 & 31 & 33 & \\
\hline
\end{tabular}




\begin{tabular}{|c|c|c|c|c|c|c|c|}
\hline \multirow[t]{2}{*}{9} & \multirow{2}{*}{$\begin{array}{l}\text { How much are the } \\
\text { values of your } \\
\text { ethnic heritage } \\
\text { culture a part of } \\
\text { your life? }\end{array}$} & W & 5 & 8 & 24 & 129 & \multirow[b]{2}{*}{.058} \\
\hline & & $\mathrm{M}$ & 5 & 15 & 43 & 183 & \\
\hline \multirow[t]{2}{*}{10} & $\begin{array}{l}\text { How important is it } \\
\text { to you to celebrate }\end{array}$ & W & 4 & 2 & 16 & 144 & \multirow[b]{2}{*}{$.143 *$} \\
\hline & $\begin{array}{l}\text { holidays in the ways } \\
\text { of your } \\
\text { ethnic/heritage } \\
\text { culture? }\end{array}$ & $\mathrm{M}$ & 0 & 9 & 29 & 208 & \\
\hline \multirow[t]{2}{*}{11} & $\begin{array}{l}\text { How important is it } \\
\text { to you to grow up }\end{array}$ & W & 4 & 2 & 17 & 143 & \multirow[b]{2}{*}{$.159 *$} \\
\hline & $\begin{array}{l}\text { with values of your } \\
\text { ethnic/heritage } \\
\text { culture? }\end{array}$ & $\mathrm{M}$ & 1 & 9 & 45 & 191 & \\
\hline \multirow[t]{2}{*}{12} & $\begin{array}{l}\text { How important is it } \\
\text { to you to speak in }\end{array}$ & W & 5 & 5 & 13 & 143 & \multirow[b]{2}{*}{$.158^{*}$} \\
\hline & $\begin{array}{l}\text { the language of your } \\
\text { ethnic/heritage } \\
\text { culture? }\end{array}$ & $\mathrm{M}$ & 1 & 13 & 37 & 195 & \\
\hline \multirow[t]{2}{*}{13} & $\begin{array}{l}\text { How important is it } \\
\text { to you to wear the }\end{array}$ & W & 5 & 5 & 26 & 130 & \multirow[b]{2}{*}{$.216^{* * * *}$} \\
\hline & $\begin{array}{l}\text { dresses of your } \\
\text { ethnic/heritage } \\
\text { culture? }\end{array}$ & M & 4 & 33 & 59 & 150 & \\
\hline \multirow[t]{2}{*}{14} & $\begin{array}{l}\text { How much do you } \\
\text { enjoy eating foods }\end{array}$ & W & 2 & 4 & 22 & 138 & \multirow[b]{2}{*}{$.143^{*}$} \\
\hline & $\begin{array}{l}\text { of your } \\
\text { ethnic/heritage } \\
\text { culture? }\end{array}$ & $\mathrm{M}$ & 0 & 18 & 40 & 188 & \\
\hline \multirow[t]{2}{*}{15} & How much do you & W & 3 & 9 & 53 & 101 & \multirow[b]{2}{*}{.109} \\
\hline & $\begin{array}{l}\text { your ethnic/heritage } \\
\text { culture? }\end{array}$ & M & 7 & 28 & 70 & 141 & \\
\hline \multirow[t]{2}{*}{16} & $\begin{array}{l}\text { How important is it } \\
\text { to you to marry }\end{array}$ & W & 2 & 5 & 16 & 143 & \multirow[b]{2}{*}{.049} \\
\hline & $\begin{array}{l}\text { someone belonging } \\
\text { to your ethnic } \\
\text { heritage culture? }\end{array}$ & M & 4 & 10 & 29 & 203 & \\
\hline
\end{tabular}

Note. $\mathrm{W}=$ Women, $\mathrm{M}=\mathrm{Men} ; * p<.05, * * * p<.001$.

Table 4 depicts intercorrelations between perceived parental acceptance (maternal and paternal), psychological adjustment, and youths' attitude towards culture (national and heritage). 
Table 4

Correlations between Maternal Acceptance, Paternal Acceptance, Attitudes toward Heritage Culture, National Culture, and Psychological Adjustment of the Respondents

\begin{tabular}{lccccc}
\hline Variables & 1 & 2 & 3 & 4 & 5 \\
\hline 1. Maternal acceptance & ---- & & & & \\
2. Paternal acceptance & $.54^{* *}$ & ---- & & & \\
3. Heritage culture & $-.18^{* *}$ & $-.22^{* *}$ & ---- & & \\
4. National culture & -.01 & .02 & $-.30^{* *}$ & ---- & \\
5. Psychological adjustment & $.35^{* *}$ & $.36^{* *}$ & $-.15^{* *}$ & -.02 & ---- \\
\hline
\end{tabular}
** $p<.01$.

Results in Table 4, showed that there were significant correlations between maternal acceptance and psychological adjustment, and also between maternal acceptance and heritage cultural orientation of the respondents. Similarly, there are significant correlations between paternal acceptance and psychological adjustment, and also between paternal acceptance and heritage cultural orientation of the respondents. But there were no significant correlations between maternal and paternal acceptance with the national cultural orientation of the respondents. As there were no significant correlations between maternal acceptance, paternal acceptance, and psychological adjustment with the national cultural orientation of the respondents, the national cultural orientation was excluded from the subsequent analyses.

To examine the independent contributions of maternal acceptance, paternal acceptance, and psychological adjustment on the heritage cultural orientation of Bangladeshi youths, a multiple regression analysis was conducted (see Table 5) with maternal acceptance, paternal acceptance, and psychological adjustment as predictive variables, and the heritage culture as the outcome variable. The results showed that only paternal acceptance had a significant independent effect on the heritage culture of the respondents.

Table 5

Multiple Regression Analyses of Maternal Acceptance, Paternal Acceptance and Psychological Adjustment as Predictors of Heritage Cultural Attitudes of the Respondents

\begin{tabular}{|c|c|c|c|c|c|c|c|}
\hline \multirow[t]{2}{*}{ Variable } & \multirow[t]{2}{*}{$B$} & \multicolumn{2}{|c|}{$95 \%$ CI for B } & \multirow[t]{2}{*}{$S E B$} & \multirow[t]{2}{*}{$\beta$} & \multirow[t]{2}{*}{$R^{2}$} & \multirow[t]{2}{*}{$\Delta R^{2}$} \\
\hline & & $L L$ & $U L$ & & & & \\
\hline & & & & & & $.06^{* * *}$ & $.05 * * *$ \\
\hline Constant & $34.21 * * *$ & 31.78 & 36.65 & 1.24 & & & \\
\hline Maternal acceptance & -.03 & -.08 & .02 & .02 & -.07 & & \\
\hline Paternal acceptance & $-.05 * *$ & -.09 & -.01 & .02 & $-.16^{* *}$ & & \\
\hline $\begin{array}{l}\text { Psychological } \\
\text { adiustment }\end{array}$ & -.02 & -.05 & .01 & .01 & -.07 & & \\
\hline
\end{tabular}

$* * p<.01 . * * * p<.001$.

Further, to investigate the independent contributions of maternal acceptance, paternal acceptance, and cultural orientation on psychological adjustment of the respondents, a multiple regression analysis was performed (see Table 6) with maternal acceptance, paternal acceptance, and heritage cultural orientation as predictive variables, and psychological adjustment as the outcome variable. The results showed that both paternal and maternal acceptance had significant independent effects on the psychological adjustment of the respondents. But the heritage cultural 
orientation had no significant independent contribution on the psychological adjustment of Bangladeshi ethnic minority youths.

\section{Table 6}

Multiple Regression Analyses of Maternal Acceptance, Paternal Acceptance and Heritage Culture as Predictors of Psychological Adjustment of the Respondents

\begin{tabular}{|c|c|c|c|c|c|c|c|}
\hline \multirow[t]{2}{*}{ Variable } & \multirow[t]{2}{*}{$B$} & \multicolumn{2}{|c|}{$95 \%$ CI for $B$} & \multirow[t]{2}{*}{$S E B$} & \multirow[t]{2}{*}{$\beta$} & \multirow[t]{2}{*}{$R^{2}$} & \multirow[t]{2}{*}{$\Delta R^{2}$} \\
\hline & & $L L$ & $U L$ & & & & \\
\hline & & & & & & $.17 * * *$ & $.17 * * *$ \\
\hline Constant & $74.11^{* * *}$ & 61.38 & 86.85 & 6.48 & & & \\
\hline Maternal acceptance & $.34 * * *$ & .18 & .50 & .08 & $22 * * *$ & & \\
\hline Paternal acceptance & $.29 * * *$ & .16 & .42 & .07 & $.23 * * *$ & & \\
\hline Heritage culture & -.23 & -.58 & .12 & .18 & -.06 & & \\
\hline
\end{tabular}
$* * * p<.001$.

\section{Discussion}

As noted earlier, major objectives of the study were to examine relations between parental acceptance, maternal acceptance, bicultural attitudes, and psychological adjustment of the Bangladeshi ethnic minority youth; and also, to compare independent effects of paternal and maternal acceptance on the bicultural attitudes, and psychological adjustment of the respondents. The overall findings reveal significant relations between parental acceptance, maternal acceptance, bicultural attitudes, and psychological adjustment of the youth. The results also show stronger independent effects of parental acceptance than maternal acceptance on the young adults' heritage cultural orientation and psychological adjustment. The following section contains more detailed discussion about how the results compare and contrast with the relevant previous studies.

Findings of this study reveal that the majority of Bangladeshi ethnic youth, regardless of gender, tend to be biculturally oriented, although both the young men and women consider their heritage cultural values to be a more essential part of their lives than the national cultural values, but the young women expressed stronger feeling for heritage culture than did the young men.

Thus, the results indicate a tendency of the young men more than young women for cultural adaptation, accommodation, and adjustment with the national culture along with their heritage culture. The findings seem to support the existing acculturation literature which shows that generally young people, especially young men, tend to acculturate rapidly with the national culture (Gil et al., 1994; Khaleque et al., 2015; Szapocznik et al., 1990.) Findings of acculturation research suggest that a fundamental element of healthy intergroup relationships is the mutual respects and positive attitudes of the majority and the minority ethnic groups toward each other's cultural values (Berry, 2001). A positive attitude implies a combination of positive views on cultural maintenance of ethnic groups and appreciation of the need for accommodation of diversity in an equitable way (Berry, 2001; Citrin et al., 1997). Research evidence further shows that cultural diversity-bicultural or multicultural ideology of a society, greatly influences the acculturation process and cultural adaptation of the ethnic majority and minority communities (Arends-Tóth, \& Van de Vijver, 2003)

The results of this study further reveal that in comparison to young men, significantly greater proportion of the young women tend to have stronger affinity for some components of their heritage culture including, food, dress, language, and marriage with someone belonging to their heritage culture. Contrarily, significantly greater proportion of the young men than women have 
stronger affinity for some components of the national culture including national language, dress, and marriage with someone belonging to other cultures. These findings are consistent with that of several other studies which show that women generally tend to be more uniculturally oriented toward their heritage culture, and men tend to more biculturally oriented toward both the heritage and the national cultures (Khaleque et al., 2015; Khaleque et al., 2008; Khaleque et al., 2016). A likely reason for this gender difference seems to be the fact that in oriental culture women tend to be less exposed than men to members of other ethnic groups. Moreover, unlike minority ethnic women, men are likely to be more exposed to other cultures and have more social and cultural interactions with people from other cultures (Khaleque et al., 2015).

In addition, the results show that the heritage cultural orientation (not the national cultural orientation) has significant correlation with the psychological adjustment of the Bangladeshi ethnic youth regardless of gender. This finding is consisted with some findings which showed strong relationships between psychological wellbeing and heritage cultural values (Cauce \& DomenechRodriguez, 2002; Katsantonis, 2020; Priest et al., 2016). The most likely reason for this positive relationship is the fact that individuals who have positive attitude toward their heritage culture are likely to get family support to integrate the heritage culture values with the national culture values (Perez-Brena et al., 2018), and they tend to make better adjustment in a bicultural or multicultural environment, especially when the family emphasizes the ethnic-racial socialization of its members (Nguyen et al., 2015). Family often influences cultural transition, intercultural integration, social values, and psychological adjustment of its members, especially of its young members (Oppedal, 2006; Stuart et al., 2010). Moreover, the family often serves as a protective buffer for youth by providing emotional support in resolving intercultural conflict and improving adjustment (Dunbar et al., 2015; Priest et al., 2016).

Another important reason for the significant relation between the heritage cultural orientation and the psychological adjustment, seems to be fact that the youth considered their heritage cultural values as an integral part of their identity. Identity development is a critical issue during adolescence and young adulthood (Erikson, 1982). Erikson viewed adolescence and emerging adulthood as a critical period of life, because the question "who am I?" becomes important during adolescence and young adulthood. Researchers suggest that an individual's selfconcept and identity have tremendous influence on his/her behavior, self-esteem, social skill development, and psychological adjustment (Khaleque, 2018; Marsh, \& Martin, 2011).

Although the findings show that both paternal acceptance and maternal acceptance have significant independent effects on the psychological adjustment of the young men and women, only paternal acceptance has significant unique effect on their heritage cultural orientation. These findings are consistent with the interpersonal acceptance-rejection theory's prediction that perceived paternal acceptance often has stronger implications than perceived maternal acceptance for children's and adults' attitudes, behaviors and other positive developmental outcomes (Rohner, 2016). These findings are also in agreement with the findings of a growing body of cross-cultural research which shows that perceived paternal acceptance often has as great and sometimes greater impact on child and adult development than perceived maternal acceptance (Parmar \& Rohner, 2008; Rohner \& Veneziano, 2001; Veneziano, 2008). The reasons may be that in a patriarchal society, as in Bangladesh, the father is perceived as having more power and prestige than the mother in the family (Sultana \& Khaleque, 2016). Consequently, the father is likely to exercise more power and influence on children than the mother (Khaleque et al., 2013).

Although this study is based on data from a reasonably large sample, it has certain limitations. For example, the sample sizes from some ethnic groups were too small to make statistically meaningful inter-ethnic comparisons. In addition, it was not possible to know how 
acculturation patterns change over individuals' lifespan, because it was not a longitudinal study. Nevertheless, the present study provides some valuable findings about the cultural orientation patterns and the psychological adjustment of the ethnic minority youth in Bangladesh. This study is likely to add to the scanty literature on interethnic relationships, especially in the developing countries. However, further research with longitudinal design seems to be necessary to better understand changes in cultural orientation patterns of the ethnic minorities over time globally.

The findings of this study suggest the following important messages for professionals and practitioners globally:

- The majority of the Bangladeshi ethnic minority youth tended to be biculturally oriented.

- Although both the young men and women considered their heritage cultural values to be a more essential part of their lives than the national cultural values, but the young women expressed stronger feeling for heritage culture than did the young men.

- Significantly greater number of young women expressed stronger affinity for some components of their heritage culture, such as cultural identity, food, dress patterns, language, and marriage system. Whereas, significantly greater number of the young men expressed stronger affinity for some components of the national culture, including cultural values, language, dress patterns, and marriage system.

- Both paternal and maternal acceptance have significant independent effects on the psychological adjustment of the youth.

- But paternal acceptance has stronger effect than maternal acceptance on the heritage cultural orientation and psychological adjustment of the ethnic minority young adults, regardless of gender.

\section{Funding Information}

The authors received no fund from any source for this study.

\section{Conflict of Interest to Declare}

The authors declare no conflict of interest.

\section{References}

Arends-Tóth, J., \& Van De Vijver, F. J. R. (2003). Multiculturalism and acculturation: Views of Dutch and Turkish-Dutch. European Journal of Social Psychology, 33(2), 249-266. https://doi.org/10.1002/ejsp.143

Balidemaj, A. (2016). Acculturation, ethnic identity, and psychological well-being of AlbanianAmerican immigrants in the United States [Doctoral dissertation, Clemson University]. TigerPrints. https://tigerprints.clemson.edu/cgi/viewcontent.cgi?article=2636\&context=all_dissertatio ns

Benet-Martínez, V. (2012). Multiculturalism: cultural, social, and social processes. In K. Deaux \& M. Snyder (Eds.), The Oxford handbook of personality and social psychology (pp. 623648). Oxford University Press. 
Benet-Martinez, V., \& Haritatos, J. (2021). Bicultural identity integration (BII): Components and psychosocial antecedents. https://doi.org/escholarship.org/content/qt4vh6z3s2/qt4vh6z3s2_noSplash_00893f9bd923 aab31fd1fdba35482e45.pdf?t=lnoxus

Benet-Martinez, V., Lee, F., \& Leu, J. (2006). Biculturalism and cognitive complexity: Expertise in cultural representations. Journal of Cross-Cultural Psychology, 37(4), 386-407. https://doi.org/10.1177/0022022106288476

Berry, J. W. (1997). Immigration, acculturation, and adaptation. Applied Psychology: An International Review, 46(1), 5-34. https://doi.org/10.1111/j.1464-0597.1997.tb01087.x

Berry, J. W. (2001). A psychology of immigration. Journal of Social Issues, 57(3), 615-631. https://doi.org/10.1111/0022-4537.00231

Berry, J. W. (2005). Acculturation: Living successfully in two cultures. International Journal of Intercultural Relations, 29(6), 697-712. https://doi.org/10.1016/j.jintrel.2005.07

Berry, J. W. (2006). Acculturation: A conceptual overview. In M. H. Bornstein \& L. B. Cote (Eds.), Acculturation and parent-child relationships (pp. 13-30). Erlbaum Associates.

Berry, J. W., Phinney, J. S., Sam, D. L., \& Vedder, P. (Eds.). (2006). Immigrant youth in cultural transition: Acculturation, identity and adaptation across national contexts. Lawrence Erlbaum Associates.

Cauce, A. M., \& Domenech-Rodríguez, M. (2002). Latino families: Myths and realities. In J. Contreras, A. Neal-Barnett, \& K. Kerns (Eds.), Latino children and families in the United States: Current research and future directions (pp. 3-26). Praeger.

Citrin, J., Green, D. P., Muste, C., \& Wong, C. (1997). Public opinion toward immigration reform: The role of economic motivations. Journal of Politics, 59(3), 858-881. https://doi.org/10.2307/2998640

Cortes, D. E., Rogler, L. H., \& Malgady, R. G. (1994). Biculturality among Puerto Rican adults in the United States. American Journal of Community Psychology, 22(5), 707-721. https://doi.org/10.1007/bf02506900

Dunbar, A. S., Perry, N. B., Cavanaugh, A. M., \& Leerkers, E. M. (2015). African American parents' racial socialization profiles and young adults' emotional adaptation. Cultural Diversity \& Ethnic Minority Psychology, 21(3), 409-419. https://doi.org/10.1037/a0037546

Erikson, E. H. (1982). Identity and the life cycle. Norton.

Fazel, M., \& Betancourt, T. S. (2018). Preventive mental health interventions for refugee children and adolescents in high-income settings. The Lancet Child \& Adolescent Health, 2(2), 121132. https://doi.org/10.1016/s2352-4642(17)30147-5

Friedman, H. (2012). Personality: Classic theories and modern research. Pearson Higher Education.

Gil, A. G., Vega, W. A., \& Dimas, J. M. (1994). Acculturative stress and personal adjustment among Hispanic adolescent boys. Journal of Community Psychology, 22(1), 43-54. https://doi.org/10.1002/1520-6629(199401)22:1<43: AID-JCOP2290220106>3.0.CO;2-T

Gordon, M. N. (1964). Assimilation in American life. Oxford University Press.

International Organization of Migration. (2020). United Nations World Migration Report. https://www.un.org/sites/un2.un.org/files/wmr_2020.pdf

Juang, L. P., \& Schachner, M. K. (2020). Cultural diversity, migration and education. International Journal of Psychology, 55(5), 695-701. https://doi.org/10.1002/ijop.12702 
Katsantonis, I. (2020). Factors Associated with Psychological Well-Being and Stress: A CrossCultural Perspective on Psychological Well-Being and Gender Differences in a Population of Teachers. Pedagogical Research, 5(4), em0066. https://doi.org/10.29333/pr/8235

Khaleque, A. (2006). Psychometric properties of a bicultural attitude scale [Unpublished manuscript]. Department of Human Development and Family Studies, University of Connecticut.

Khaleque, A. (2008). Psychometric properties of a bicultural attitude scale. Frontier Women's University Journal of Social Sciences, 2, 18-25.

Khaleque, A. (2011). Revised bicultural attitude scales [Unpublished manuscript]. Department of Human Development and Family Studies, University of Connecticut.

Khaleque, A. (2014). Revised bicultural attitude scales [Unpublished manuscript]. Department of Human Development and Family Studies, University of Connecticut.

Khaleque, A. (2015). Perceived parental neglect, and children's psychological maladjustment and negative personality dispositions: A meta-analysis of multicultural studies. Journal of Child \& Family Studies, 24, 1419-1428. https://doi.org/10.1007/s10826-014-9948-x

Khaleque, A. (2016). Psychometric properties of two bicultural attitude scales: An update. Psychological Studies, 61(4), 288-294. https://doi.org/10.1007/s12646-016-0372-8

Khaleque, A. (2017). Perceived parental hostility and aggression, and children's psychological maladjustment, and negative personality dispositions: A meta-analysis. Journal of Child \& Family Studies, 26, 977-988. https://doi.org/10.1007/s10826-016-0637-9

Khaleque, A. (2018). Intimate relationships across the lifespan: Formation, development, enrichment, and maintenance. Praeger.

Khaleque, A. (2020). Bangladeshi families. In S. S. Chuang, U. P. Gielen, R. Moodley, \& S. Akram-Paul (Eds.), Asian families in Canada and the United States: Implications for mental health and well-being (pp. 125-139). Springer.

Khaleque, A. (2021). Parenting and child development: Across ethnicity and culture. Praeger.

Khaleque, A., \& Ali, S. (2017). A systematic review of meta-analyses of research on interpersonal acceptance-rejection theory: Constructs and measures. Journal of Family Theory \& Review, 9(4), 441-458. https://doi.org/10.1111/jftr.12228

Khaleque, A., Malik, F., \& Rohner, R. P. (2015). Differential acculturation among Pakistani American immigrant parents and children. Psychological Studies, 60(4), 407-411. https://doi.org/10.1007/s12646-015-0337-3

Khaleque, A., \& Rohner, R. P. (2000). Analysis of the reliability and validity of the PARQ, $P A R Q / C o n t r o l$, and $P A Q$. (Available from the Rohner Center for the Study of Interpersonal Acceptance and Rejection, Department of Human Development and Family Sciences, University of Connecticut at Storrs).

Khaleque, A., \& Rohner, R. P. (2002). Reliability of measures assessing the pancultural association between perceived parental acceptance-rejection and psychological adjustment: A metaanalysis of cross-cultural and intracultural studies. Journal of Cross-Cultural Psychology, 33, 87-99. https://doi.org/10.1177/0022022102033001006

Khaleque, A., Rohner, R. P., Nahar, Z., \& Sharif, A. H. (2008). Acculturation and perceived parental acceptance-rejection, control, and psychological adjustment of Bangladeshi immigrant children and parents in America. In F. Erkman (Ed.), Acceptance: The essence of peace (225-236). Turkish Psychological Association.

Khaleque, A., Shirin, A., \& Uddin, M. K. (2013). Attachment relationships and psychological adjustment of married adults. Social Indicators Research, 110(1), 237-244. https://doi.org/10.1007/s11205-011-9926-2 
Khaleque, A., Uddin, M. K., Roy, K., Aktar, R., Siddique, M. N., \& Rohner, R. P. (2016, February 17-20). Bicultural attitude and psychological adjustment of ethnic minority adults in Bangladesh [Paper presentation]. The Society for Cross Cultural Research Conference, Portland, OR, USA.

Kim, E., Han, G., \& McCubbin, M. A. (2007). Korean American maternal acceptance-rejection, acculturation, and children's social competence. Family \& Community Health, $30(2$ Suppl.), S33-S45. https://doi.org/10.1097/01.fch.0000264879.88687.32

Marsh, H. W., \& Martin, A. J. (2011). Academic self-concept and academic achievement: Relations and causal ordering. British Journal of Educational Psychology, 81(1), 59-77. https://doi.org/10.1348/000709910x503501

Meca, A., Elchas, K., Schwartz, S. J., \& Davis, R. (2019). Biculturalism and bicultural identity development.

https://doi.org/researchgate.net/publication/337230415_Biculturalism_and_bicultural_ide ntity_development

Nguyen, A. M. D., \& Benet-Martinez, V. (2013). Biculturalism and adjustment: A meta-analysis. $\begin{array}{llll}\text { Journal of Cross-Cultural Psychology, } & 44(1),\end{array}$ https://doi.org/10.1177/0022022111435097

Nguyen, C. P., Wong, Y. J., Juang, L. P., \& Park, I. J. K. (2015). Pathways among Asian Americans' family ethnic socialization, ethnic identity, and psychological well-being: A multigroup mediation model. Asian American Journal of Psychology, 6(3), 273-280. https://doi.org/10.1037/aap0000026

Oetting, E. R., \& Beauvais, F. (1990). Orthogonal cultural identification theory: The cultural identification of minority adolescents. The International Journal of the Addictions, 25(5 Suppl.), 655-685. https://doi.org/10.3109/10826089109077265

Oppedal, B. (2006). Development and acculturation. In D. L. Sam \& J. W. Berry (Eds.), The Cambridge handbook of acculturation psychology (p. 97-112). Cambridge University Press.

Parmer, P., \& Rohner, R. P. (2008). Relations among spouse acceptance, remembered parental acceptance in childhood, and psychological adjustment among married adults in India. Cross-Cultural Research, 42(1), 57-66. https://doi.org/10.1177/1069397107309763

Partha, R. (2014, May 15-18). Socio-cultural impacts of Bengali resettlement project on the indigenous people in the Chittagong hill tracts (CHT) of Bangladesh [Paper presentation]. The joint conference of the Japanese Society of Anthropology and International Union of Anthropological and Ethnological Sciences, Tokyo, Japan.

Podio-Guidugli, S. (2010). Parenting in a context of acculturation: An empirical study on the Filipino community in Rome [Unpublished doctoral dissertation]. University La Sapienza.

Prez-Brena, N. J., Rivas-Drake, D., Toomey, R. B., \& Umana-Taylor, A. J. (2018). Contribution of the integrative model for the study of developmental competence in minority children: What have we learned about adaptive culture. American Psychologist,73(6), 713-726. https://doi.org/10.1037/amp0000292

Priest, N., Walton, J., White, F., Kowal, E., Fox, B., \& Paradies, Y. (2016). 'You are not born being racist, are you?' Discussing racism with primary aged-children. Race, Ethnicity and Education, 19(4), 808-834. https://doi.org/10.1080/13613324.2014.946496

Rasool, S., \& Zhang, J. (2020). Bangladeshi, Indian, and Pakistani Parents' Perceptions of Their Children's Academic Achievement in Southwest Florida. American Journal of Qualitative Research, 4(3), 146-160. https://doi.org/10.29333/ajqr/9337 
Rohner, R. P. (1986). The warmth dimension: foundations of parental acceptance-rejection theory. Sage Publications, Inc.

Rohner, R. P. (2016). Introduction to interpersonal acceptance-rejection theory, methods, evidence, and implications. University of Connecticut, Ronald and Nancy Rohner Center for the Study of Interpersonal Acceptance Rejection. http://csiar.uconn.edu/

Rohner, R. P. (2020). Introduction to interpersonal acceptance-rejection theory. https://csiar.uconn.edu/introduction-to-partheory/

Rohner, R. P. (2021). Introduction to interpersonal acceptance-rejection theory (IPARTheory) https://csiar.uconn.edu/wp-content/uploads/sites/494/2019/12/Introduction-toIPARTheory-for-web-1.pdf

Rohner, R. P., \& Carrasco, M. A. (Eds.). (2014). Parental power and prestige moderate the effects of perceived acceptance on offspring's psychological adjustment [Special Issue]. CrossCultural Research, 48,3.

Rohner, R. P., \& Khaleque, A. (2005). Handbook for the study of parental acceptance and rejection (4th ed.). Rohner Research Publications.

Rohner, R. P., \& Khaleque, A. (2010). Testing central postulates of parental acceptance-rejection theory (PARTheory): A meta-analysis of cross-cultural studies. Journal of Family Theory and Review, 2(1), 73-87. https://doi.org/10.1111/j.1756-2589.2010.00040.x

Rohner, R., Khaleque, A., \& Cournoyer, D. E. (2013). Parental acceptance-rejection theory, methods, evidence and implications. http://vm.uconn.edu/ rohner.

Rohner, R. P., \& Veneziano, R A. (2001). The importance of father love: History and contemporary evidence. Review of General Psychology, 5(4), 382-405. https://doi.org/10.1037/10892680.5.4.382

Sam, D. L. (2000). Psychological adaptation of adolescents with immigrant backgrounds. The Journal of Social Psychology, 140(1), 5-25. https://doi.org/10.1080/00224540009600442

Sorenson, S. B., \& Golding, J. M. (1988). Suicide ideation and attempts in Hispanics and nonHispanic Whites: Demographic and psychiatric disorder issues. Suicide and lifethreatening behavior, 18(3), 205-218. https://doi.org/10.1111/j.1943-278x.1988.tb00157.x

Stuart, J., Ward, C., Jose, P. E., \& Narayanan, P. (2010). Working with and for communities: A collaborative study of harmony and conflict in well-functioning, acculturating families. International Journal of Intercultural Relations, 34(2), 114-126. https://doi.org/10.1016/j.ijintrel.2009.11.004

Sultana, S. \& Khaleque, A. (2016). Differential effects of perceived maternal and paternal acceptance on male and female adult offspring's psychological adjustment. Gender Issues, 33(1), 42-52. https://doi.org/ 10.1007/s12147-015-9147-0.

Szapocznik, J., Kurtines, W., Santisteban, D. A., \& Rio, A. T. (1990). Interplay of advances between theory, research, and application in treatment interventions aimed at behavior problem children and adolescents. Journal of Consulting \& Clinical Psychology, 58(6), 696-703. https://doi.org/10.1037/0022-006x.58.6.696

Uddin, M. K., \& Aktar, R. (2014a). Bangla translation of the Adult version of the Parental Acceptance-Rejection Questionnaire for Fathers and Mothers (Adult PARQ-Short form: Father and Mother). Department of Psychology, University of Dhaka.

Uddin, M. K., \& Aktar, R. (2014b). Bangla translation of the Adult version of the Personality Assessment Questionnaire (Adult PAQ-Short form). Department of Psychology, University of Dhaka.

Uddin, M. K., Aktar, R., \& Roy, K. (2014). Bangla translation of the Bicultural Attitude Scale (BAS) for Youth. Department of Psychology, University of Dhaka. 
Veneziano, R. A. (2008, July 3 - 6). The relative importance of fathers versus mothers for offspring's behavior: Theory and implications for future research [Paper presentation]. The Second International Congress on Interpersonal Acceptance and Rejection, University of Crete, Rethymno, Greece.

Worldometer. (2020). Bangladesh population. https//: www.worldometers.info» world-population

\section{Notes on Contributors}

Abdul Khaleque, $\mathrm{PhD}$, is an adjunct professor (retired), and senior scientist in the Rohner Center at the Department of Human Development and Family Sciences, University of Connecticut, USA. His research interests include interpersonal relations, psychological adjustment, and personality development of individuals across ethnicity and culture. He has been serving as a member of the editorial board and as a reviewer of over a dozen of international journals. He has authored and coauthored about 120 research articles, 42 book chapters, and 14 books in psychology and human development. One of his books: Intimate Relationship Across the Lifespan, published in 2018 by the ABC-CLIO/Praeger Publications, has won two prestigious international awards (IPPY Awards) in 2019. His most recent book: Parenting and Child Development Across Ethnicity and Culture, was published in March 2021 by the Praeger Publication, Santa Barbara, California, and Denver, Colorado, USA. His ORCID ID [] is: https://orcid.org/0000-0003-3823-1034

Muhammad Kamal Uddin, PhD, is a professor of psychology at the University of Dhaka, Bangladesh. He earned PhD degree in Psychology from Kyushu University, Fukuoka, Japan. His research interests focus on school psychology, psychometrics, parental acceptance-rejection and psychological adjustment of children and adults across culture. He has authored and coauthored about 70 research articles, 2 book chapters, 3 books (including edited books) in psychology. He has been serving as consulting editor and a regular reviewer of a number of international reputed journals. He can be reached at kamaluddin67@hotmail.com His ORCID ID [D] is https://orcid.org/0000-0003-2033-8933

Rumana Aktar, $\mathrm{PhD}$, is an associate professor of psychology at the University of Chittagong, Bangladesh. She received her PhD degree in psychology from Nagoya University, Nagoya, Japan. The area of her PhD study was life-span developmental psychology. She has published a number of research articles in international reputed journals. Her research interests include psychometrics, positive psychology, as well as interpersonal relations and their consequences for individuals and societies across culture. She can be reached at rumana_psy@cu.ac.bd. Her ORCID ID [iD] is https://orcid.org/0000-0002-1299-0131 